\title{
Damage Characteristics of Surrounding Rock Subjected to VCR Mining Blasting Shock
}

\author{
Nan Jiang, ${ }^{1,2}$ Chuanbo Zhou, ${ }^{1,2}$ Xuedong Luo, ${ }^{1,2}$ and Shiwei Lu ${ }^{1,2}$ \\ ${ }^{1}$ Engineering Research Center of Rock-Soil \& Excavation and Protection, Ministry of Education, Wuhan 430074, China \\ ${ }^{2}$ Faculty of Engineering, China University of Geosciences, Wuhan 430074, China \\ Correspondence should be addressed to Chuanbo Zhou; cbzhou@cug.edu.cn
}

Received 23 July 2014; Accepted 28 September 2014

Academic Editor: Caiping Lu

Copyright (c) 2015 Nan Jiang et al. This is an open access article distributed under the Creative Commons Attribution License, which permits unrestricted use, distribution, and reproduction in any medium, provided the original work is properly cited.

For limiting the damage range caused by explosive shock loads in vertical crater retreat (VCR) mining, the blasting damage characteristics of surrounding rock were studied by two methods: numerical simulation and ultrasonic testing. Combined with the mining blasting in Dongguashan Copper Mine of China, the VCR blasting shock characteristics under different conditions are obtained by using LSDYNA. Based on statistical fracture mechanics and damage mechanics theories, a damage constitutive model for rock mass subjected to blasting shock load was established. Then by using the fast Lagrange analysis codes (FLAC3D), the blasting damage characteristics of surrounding rock were analyzed by applying the blasting shock loads obtained from the VCR mining and the damage zone is obtained. At last, the relationship between the amount of explosives and the radius of damaged surrounding rock mass was discussed, and its formula was also derived. The research provides a theoretical basis for rationally controlling stope boundaries and optimizing mining blasting parameters.

\section{Introduction}

VCR (vertical crater retreat) mining technology is widely used in mine engineering because it possesses many better features, such as higher efficiency and more simple operation. In the mining process, the blasting shock originating simultaneously from the rock-fracturing blasting load also can damage surrounding rock. For better control of the stope boundary, it is a key prospect in engineering application to ascertain damage characteristics of surrounding rock under mining blasting shock load and to optimize blasting parameters.

Damage effects of rock mass under blasting load were extensively studied at home and abroad, but these researches were mostly based on in-site tests and laboratory experiments [1-4]. In recent years, with the development of computer technology, numerical simulation was increasingly adopted to study blasting damage of rock mass [5-8]. Hao et al. analyzed the rock damage under stress wave of blasting based on an anisotropic damage constitutive model $[9,10]$. Wei et al. studied the damage of rock mass subjected to underground explosion [11]. Wang et al. analyzed the tensile damage of brittle rock mass subjected to underground explosion and the evolution characteristics of craters [12].

Based on the theories in statistical fracture mechanics and damage mechanics, a damage model for rock mass subjected to blasting load was established. At the same time, damage characteristics of surrounding rock subjected to mining blasting shock load in VCR mining and conventional blasting shock load were analyzed by numerical simulations.

\section{VCR Mining Blasting Shock Load}

2.1. Numerical Model. Dongguashan Copper Mine is located in Tongling, Anhui, China. It has the ability to produce around 4.3 million tons of copper ore annually, and its service life is 28 years. As the largest copper mine of down-hole pit mining in Asia, its mining depth is more than 1000 meters, which ranks the first among the nonferrous metal mines in Asia. The deposit is as long as more than $1800 \mathrm{~m}$ in trend, more than 500 meters wide, and $20-70 \mathrm{~m}$ thick. It is divided into panels every $100 \mathrm{~m}$, and there is an $18 \mathrm{~m}$ wide barrier pillar in each pair of adjacent panels. A panel is $100 \mathrm{~m}$ wide, 


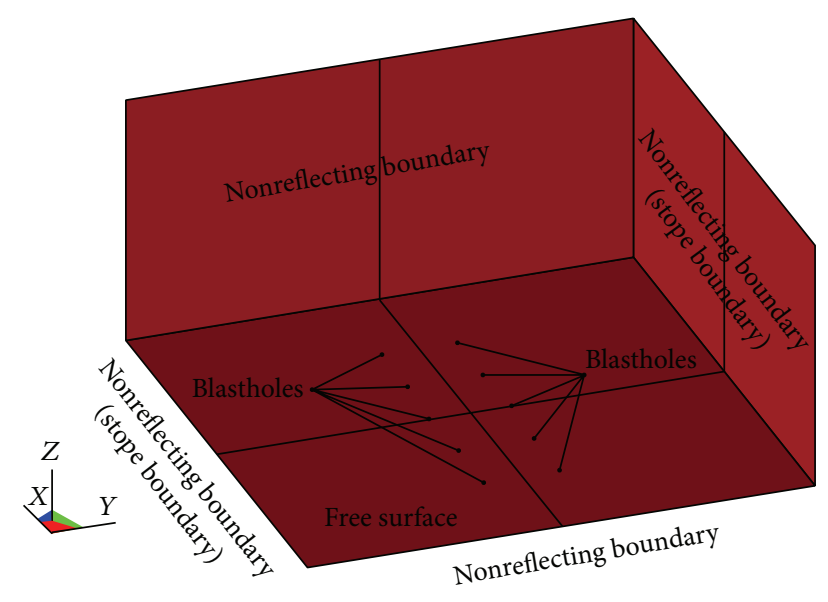

Figure 1: LSDYNA model.

TABLE 1: Parameters of the rock material.

\begin{tabular}{lcccc}
\hline $\begin{array}{l}\text { Density } \\
\left(\mathrm{g} \cdot \mathrm{cm}^{-3}\right)\end{array}$ & $\begin{array}{c}\text { Elastic modulus } \\
(\mathrm{GPa})\end{array}$ & $\begin{array}{c}\text { Poisson's } \\
\text { ratio }\end{array}$ & $\begin{array}{c}\text { Cohesion } \\
(\mathrm{MPa})\end{array}$ & $\begin{array}{c}\text { Internal } \\
\text { friction }\left({ }^{\circ}\right)\end{array}$ \\
\hline 3.22 & 69.00 & 0.31 & 21.43 & 56.21 \\
\hline
\end{tabular}

whose length and height equal the width and the thickness of the deposit, respectively. Every panel consists of 20 stopes, which are arranged along the trend of the deposit and $18 \mathrm{~m}$ wide. The room stope and pillar stope are $82 \mathrm{~m}$ long and $78 \mathrm{~m}$ long, respectively. In the mining blasting process, it is significant to control the stope boundary for safety of underground mining construction in the mine.

VCR mining method was adopted for underground mining in Dongguashan Copper Mine. According to the reality, large-diameter deep-hole blasting is introduced. The blasthole diameter is $165 \mathrm{~mm}$, the charge length is $1.5 \mathrm{~m}$ to $10.5 \mathrm{~m}$, and the stemming length is $1.2 \mathrm{~m}$ to $2.0 \mathrm{~m}$. In this study, a three-dimensional model is established using the software LS-DYNA, as shown in Figure 1, which is measuring $20 \mathrm{~m}$ in $X$-direction, $20 \mathrm{~m}$ in $Y$-direction, and $10 \mathrm{~m}$ in $Z$ direction. 10 blasting holes are equally divided into 2 rows. The distance between two rows is $3 \mathrm{~m}$, and the distance between 2 adjacent holes in the same row is $2.8 \mathrm{~m}$. Only the bottom surface is free, and the remaining surfaces are applied with nonreflecting boundary.

2.2. Calculation Parameters. In LSDYNA simulation, MohrCoulomb (M-C) model is selected as rock material's model [13]. According to the test results, parameters of stope rock mass are listed in Table 1.

The JWL state equation can simulate the relationship between pressure and specific volume in the explosion process [14]. The equation is as follows:

$$
p=A\left(1-\frac{w}{R_{1} V}\right) e^{-R_{1} V}+B\left(1-\frac{w}{R_{2} V}\right) e^{-R_{2} V}+\frac{\omega E_{0}}{V},
$$

where $A, B, R_{1}, R_{2}$, and $W$ are material constants, $P$ is pressure, $V$ is relative volume, and $E_{0}$ is specific internal energy. The physical and mechanical parameters of

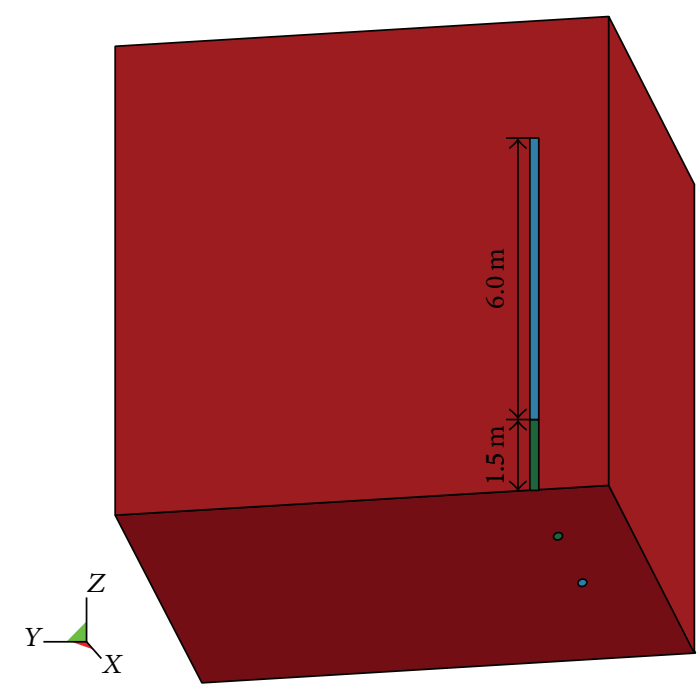

Figure 2: Numerical models with $6 \mathrm{~m}$ charging length.

TABle 2: Parameters of the explosive.

\begin{tabular}{lcccccccc}
\hline $\begin{array}{l}\text { Density } \\
\left(\mathrm{g} \cdot \mathrm{cm}^{-3}\right)\end{array}$ & $\begin{array}{c}\text { Detonation velocity } \\
\left(\mathrm{cm} \cdot \mu \mathrm{s}^{-1}\right)\end{array}$ & $\begin{array}{c}A \\
(\mathrm{GPa})\end{array}$ & $\begin{array}{c}B \\
(\mathrm{GPa})\end{array}$ & $R_{1}$ & $R_{2}$ & $\omega$ & $\begin{array}{c}E_{0} \\
(\mathrm{GPa})\end{array}$ \\
\hline 1.09 & 0.4 & 214.4 & 18.2 & 4.2 & 0.9 & 0.15 & 4.192 \\
\hline
\end{tabular}

the dynamite are the same as those of the field test and are listed in Table 2.

2.3. Blasting Load. Due to the model which is built symmetrically, a quarter of the model is calculated to reduce the size of the research object. So the model was simplified as a $10 \mathrm{~m}$ cube, and the charge length is $3 \mathrm{~m}, 3.5 \mathrm{~m}, 4.0 \mathrm{~m}, 4.5 \mathrm{~m}$, $5.0 \mathrm{~m}, 5.5 \mathrm{~m}$, and $6.0 \mathrm{~m}$, respectively. The charging length of $6.0 \mathrm{~m}$ is shown in Figure 2. The bottom surface is free; the front surface and the right surface are applied with normal displacement constraint. The remaining surfaces are applied with nonreflecting boundary, and the left sides are stope boundaries [15].

As illustrated in the rock blasting theory, the crushed zone radius is 2-3 times larger than the blasthole radius [16]. In order to obtain the blasting load applied on the crushed zone boundary, the monitoring element was selected at a horizontal distance of $0.33-0.50 \mathrm{~m}$ away from the center of the blasthole. For example, when the charge length is $6 \mathrm{~m}$, Element H54050 was selected as the monitoring element, as shown in Figure 3.

Figure 4 shows the pressure curve with time at Element H54050. Shock wave pressure applied on the boundary of crushed zone under blasting load increases to its maximum within $0.5 \mathrm{~ms}$, up to $1.74 \mathrm{GPa}$. In the same way, when the charge length is $3 \mathrm{~m}, 3.5 \mathrm{~m}, 4 \mathrm{~m}, 4.5 \mathrm{~m}, 5 \mathrm{~m}$, and $5.5 \mathrm{~m}$, the maximum shock wave pressure applied on the boundary of crushed zone under blasting load is $1.4 \mathrm{GPa}, 1.43 \mathrm{GPa}$, $1.46 \mathrm{GPa}, 1.52 \mathrm{GPa}, 1.57 \mathrm{GPa}$, and $1.61 \mathrm{GPa}$, respectively. 


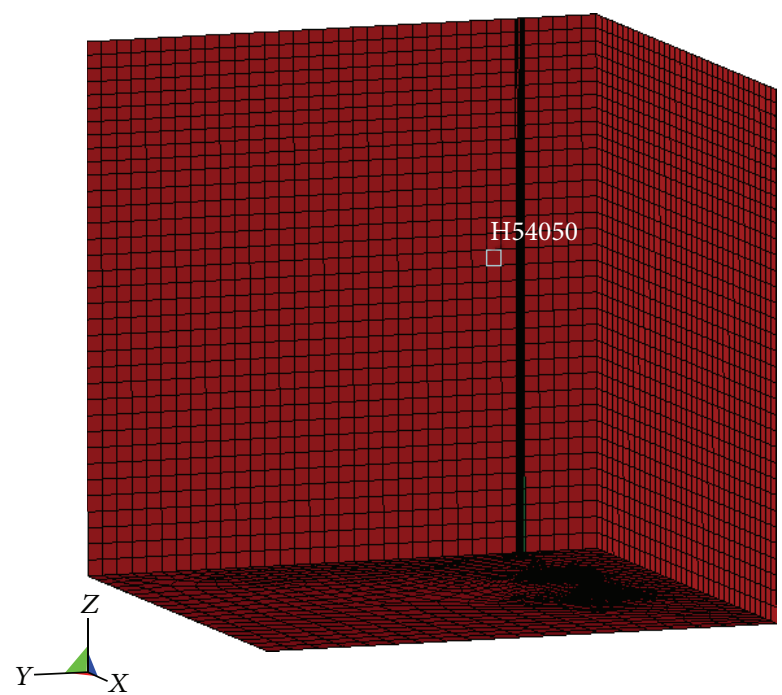

Figure 3: Monitoring element in the model with $6 \mathrm{~m}$ charging length.

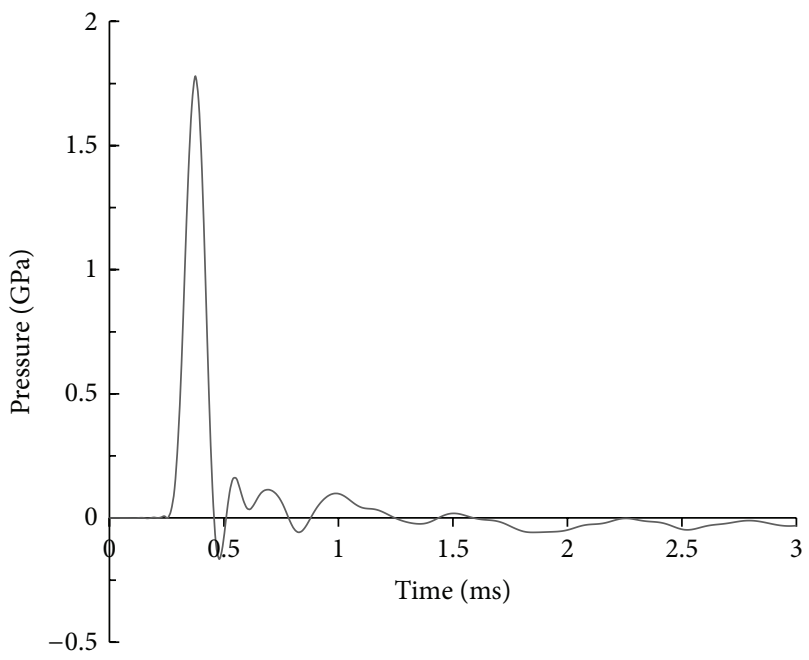

FIgURE 4: Pressure time history of Element H54050.

\section{Rock Damage Model under Blasting Shock Load}

According to statistical fractured mechanics [17], rock damage is believed to occur when the crack density reaches a given value, and the cumulation and growth of crack in rock can be demonstrated in probability terms. The following agreements have been achieved by the related research $[18,19]$ :

(1) a rock material does not fail if the applied stress is lower than its static strength;

(2) when a rock material is subjected to a stress higher than its static strength, a certain time duration is needed so that the fracture can take place;

(3) the dynamic fracture stress of a rock material is higher than its static strength and is approximately cube root dependent on the strain rate.

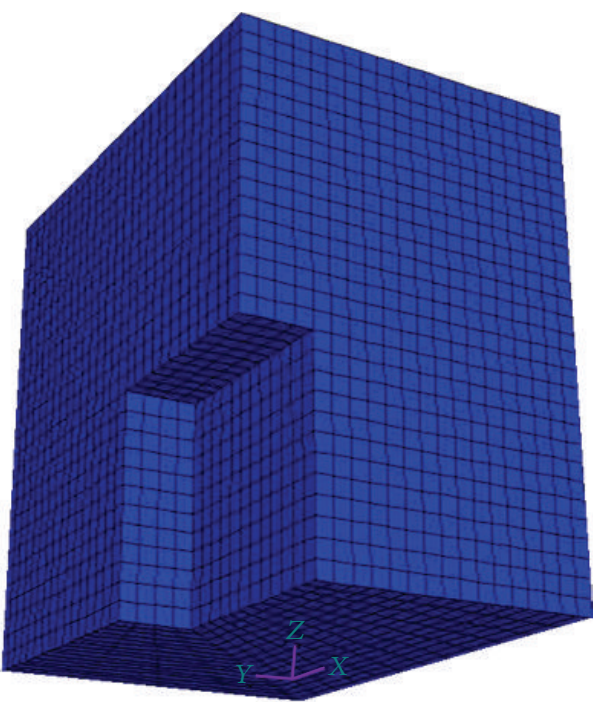

Figure 5: Numerical model with the charging length of $6 \mathrm{~m}$.

TABLE 3: Damage zone radiuses with different charge weights.

\begin{tabular}{lcc}
\hline $\begin{array}{l}\text { Charging } \\
\text { length }(\mathrm{m})\end{array}$ & $\begin{array}{c}\text { Maximum one-stage charge } \\
\text { weight }(\mathrm{kg})\end{array}$ & $\begin{array}{c}\text { Damage zone } \\
\text { radius }(\mathrm{m})\end{array}$ \\
\hline 3 & 696.75 & 5.504 \\
3.5 & 812.875 & 5.942 \\
4 & 929 & 6.478 \\
4.5 & 1045.125 & 6.763 \\
5 & 1161.25 & 7.065 \\
5.5 & 1277.375 & 7.684 \\
6 & 1393.5 & 8.141 \\
\hline
\end{tabular}

So damage due to blasting loading can be defined as the probability of fracture, written as follows:

$$
D_{i}=p_{f}=1-e^{-C_{d i}^{2}}, \quad i=1,2,3,
$$

where $p_{f}$ is the fail probability of damaged rock mass, $C_{d i}$ is the crack density in $i$ direction, and $D_{i}$ is damage value. Obviously $D_{i}$ has a value between 0 and 1, to respond to the stiffness of the intact, undamaged rock with crack density $C_{d i}=0$, and the fully fragmented rock with an infinite $C_{d i}$, respectively. Crack density is defined as follows:

$$
C_{d i}= \begin{cases}0 & \left(\varepsilon_{i} \leq \varepsilon_{\mathrm{cr} i}\right) \\ \alpha_{i}\left(\varepsilon_{i}-\varepsilon_{\mathrm{cr} i}\right)^{\beta_{i}} t & \left(\varepsilon_{i}>\varepsilon_{\mathrm{cr} i}\right),\end{cases}
$$

where $\alpha_{i}, \beta_{i}$ are material constants, $\varepsilon_{i}$ is the principle strain in $i$ direction, $\varepsilon_{\text {cri }}$ is the corresponding critical strain, and $t$ is the time to reach fracture stress. In terms of isotropic damage, the principle strain would be equivalent volume modulus.

Tensile strain is a quite important index to evaluate whether rock mass is damaged or not [20], so generally uniaxial tensile test is adopted to approximately simulate rock 


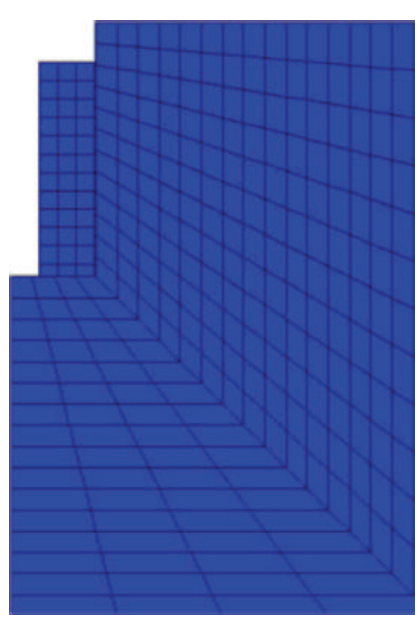

(a) $t=0.1 \mathrm{~ms}$



$\underbrace{X}_{z}$

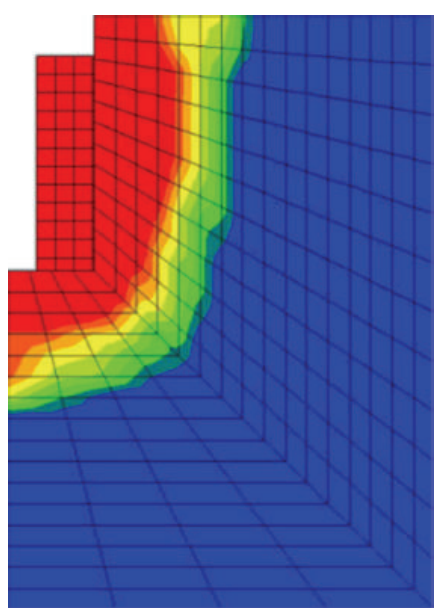

(b) $t=1.0 \mathrm{~ms}$
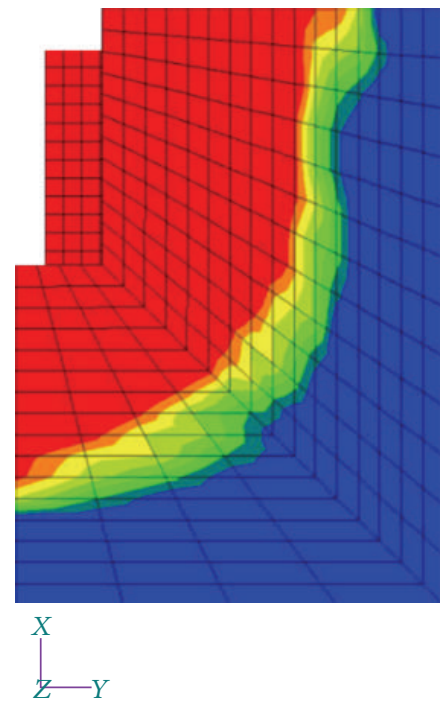

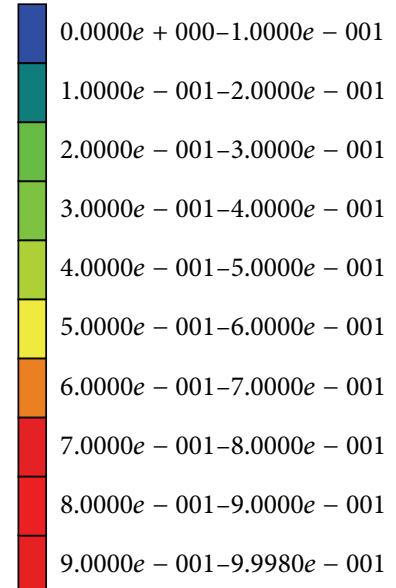

\begin{tabular}{|l}
$0.0000 e+000-1.0000 e-001$ \\
$1.0000 e-001-2.0000 e-001$ \\
$2.0000 e-001-3.0000 e-001$ \\
$3.0000 e-001-4.0000 e-001$ \\
$4.0000 e-001-5.0000 e-001$ \\
$5.0000 e-001-6.0000 e-001$ \\
$6.0000 e-001-7.0000 e-001$ \\
$7.0000 e-001-8.0000 e-001$ \\
$8.0000 e-001-9.0000 e-001$ \\
$9.0000 e-001-9.9980 e-001$
\end{tabular}

(c) $t=1.5 \mathrm{~ms}$

(d) $t=3.0 \mathrm{~ms}$

Figure 6: Damage growth on the bottom free surface.

damage. Critical strain can be obtained based on uniaxial tensile test as follows:

$$
\varepsilon_{\mathrm{cri}}=\frac{1-2 \nu}{E_{i}} \sigma_{\mathrm{st} i}, \quad i=1,2,3
$$

where $\sigma_{\text {sti }}$ is static tensile strength in $i$ direction and $E_{i}$ is equivalent elastic modulus. We define $\varepsilon_{f i}$ and $C_{d f i}$ as the tensile strain and crack density in $i$ direction when rock mass is cracked. Then $C_{d f i}$ can be expressed as follows:

$$
C_{d f i}=\alpha_{i}\left(\varepsilon_{f i}-\varepsilon_{c r i}\right)^{\beta_{i}}\left(t_{i}-t_{c i}\right), \quad i=1,2,3,
$$

where $t_{i}$ is the total time when the rock mas reaches the fracture stress and $t_{c i}$ is the time duration when the tensile strain reaches the critical value. Both of them can be obtained by

$$
\begin{aligned}
t_{i} & =\frac{\varepsilon_{f i}}{\dot{\varepsilon}_{i}}, \quad i=1,2,3, \\
t_{c i} & =\frac{\varepsilon_{\mathrm{cr} i}}{\dot{\varepsilon}_{i}}, \quad i=1,2,3,
\end{aligned}
$$

where $\dot{\varepsilon}_{i}$ is tensile strain rate. Accordingly, (5) can further be written as

$$
C_{d f i}=\alpha_{i}\left(t_{i} \dot{\varepsilon}_{i}-t_{c i} \dot{\varepsilon}_{i}\right)^{\beta_{i}}\left(t_{i}-t_{c i}\right), \quad i=1,2,3 .
$$

The time interval between the critical damage to the fracture of rock mass is given by

$$
t=t_{i}-t_{c i}=\left(\frac{C_{d f i}}{\alpha_{i}}\right)^{1 /\left(1+\beta_{i}\right)} \dot{\varepsilon}^{-\beta_{i} /\left(1+\beta_{i}\right)}, \quad i=1,2,3 .
$$




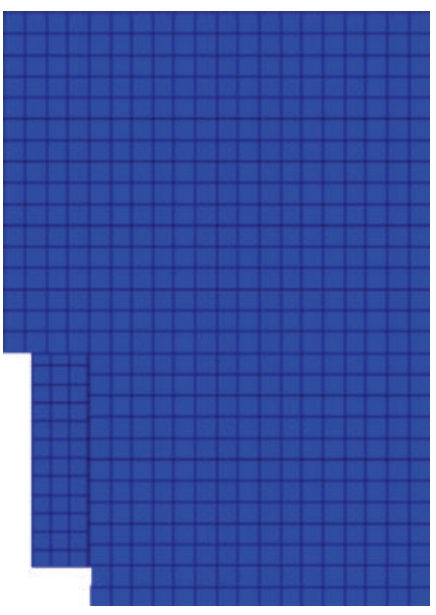

(a) $t=0.1 \mathrm{~ms}$

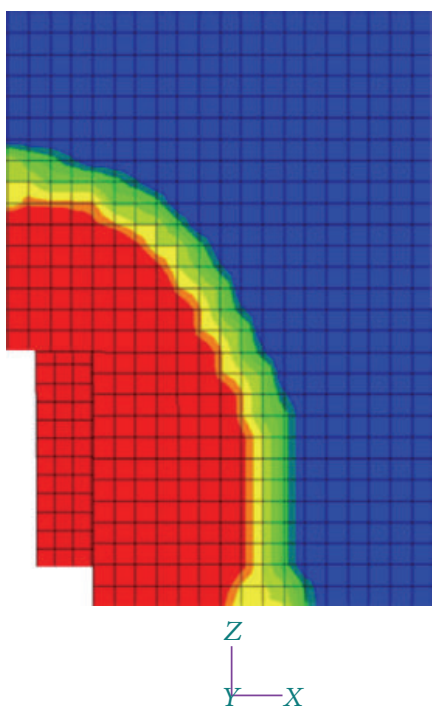

(c) $t=1.5 \mathrm{~ms}$


(b) $t=1.0 \mathrm{~ms}$
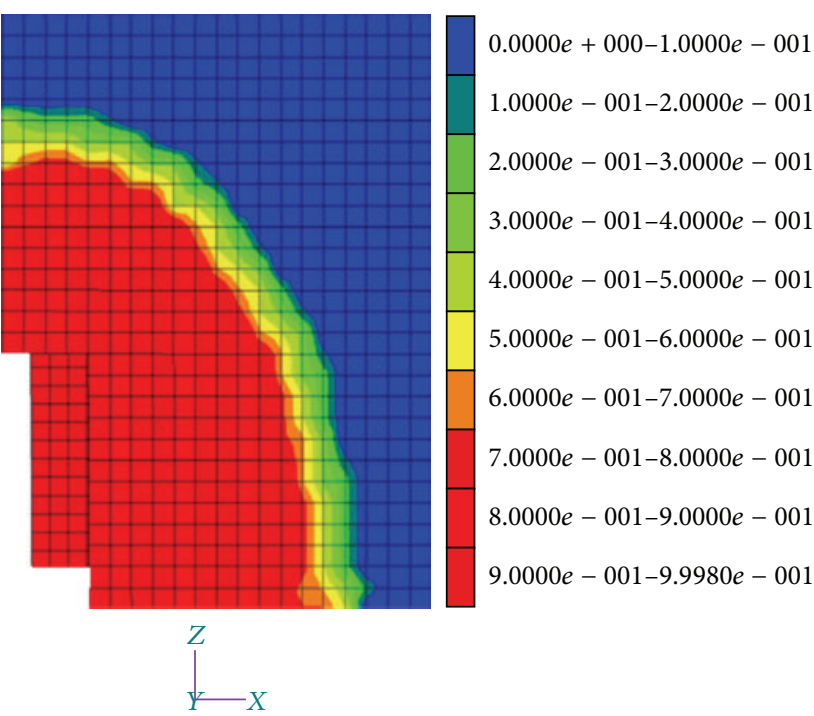

(d) $t=3.0 \mathrm{~ms}$

FIGURE 7: Damage growth along the height direction.

The relationship between the fracture stress and the corresponding strain is

$$
\sigma_{f i}=\frac{E_{i}\left(1-D_{f i}\right)}{1-2 v} \varepsilon_{f i}, \quad i=1,2,3 .
$$

Submitting (4) and (8) to (9), the strain rate dependent constitutive relation is obtained:

$$
\begin{array}{r}
\sigma_{f i}=\left(1-D_{f i}\right) \sigma_{\text {sti }}+\frac{E_{i}\left(1-D_{f i}\right)}{1-2 \nu}\left(\frac{C_{d f i}}{\alpha_{i}}\right)^{1 /\left(1+\beta_{i}\right)} \dot{\varepsilon}^{1 /\left(1+\beta_{i}\right)}, \\
i=1,2,3,
\end{array}
$$

where $D_{f i}$ is the damage variable under the fracture state and other variables are the same as previous meanings. Because the dynamic tensile strength of a rock material is higher than its static strength and is approximately cube root dependent on the strain rate, the value of $\beta$ can be given as 2 . For given $D_{\min }$ and $C_{d f}$, the material constant $\alpha_{i}$ can be calculated based on the blasting crater test results.
According to the Construction Technical Specification on Rock-Foundation Excavation Engineering of Hydraulic Structure (SL47-94), $D_{\min }$ should be 0.2 [21]. At the same time, based on the in-site tests, $\alpha_{i}$ is equal to $3.16 \times 10^{6}$, and other parameters are listed in Table 1.

\section{Numerical Analysis of Rock Damage Zone}

4.1. Numerical Model. Like the blast model above, a 3D model was established using FLAC3D. Hexahedral solid element is selected when the model is meshed. Due to the model which is built symmetrically, a quarter of the model is calculated to reduce the size of the research object. For example, when the charge length is $6 \mathrm{~m}$, a $10 \mathrm{~m}$ long, $14 \mathrm{~m}$ wide, and $14 \mathrm{~m}$ high model is established, as shown in Figure 5. The left side is the stope boundary, and the hollow part is the boundary of crushed zone of $2 \mathrm{~m} \times 6 \mathrm{~m} \times 7.5 \mathrm{~m}$. 


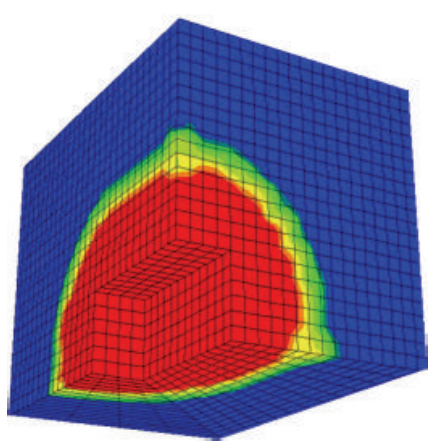

(a) Charge length is $3.0 \mathrm{~m}$

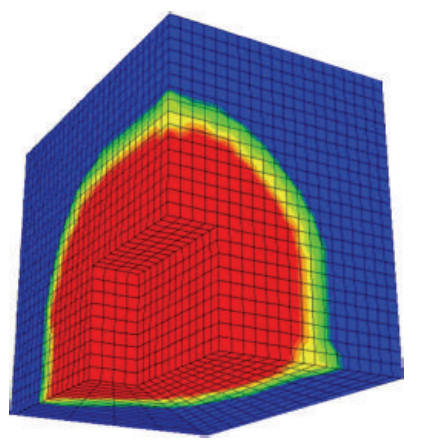

(d) Charge length is $4.5 \mathrm{~m}$

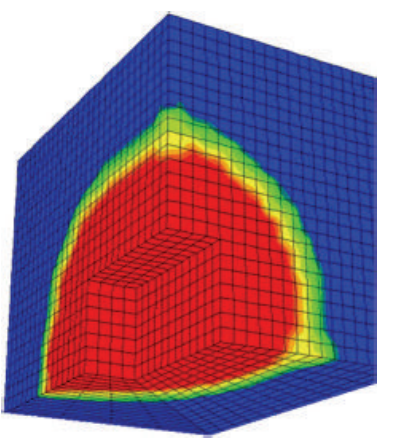

(b) Charge length is $3.5 \mathrm{~m}$

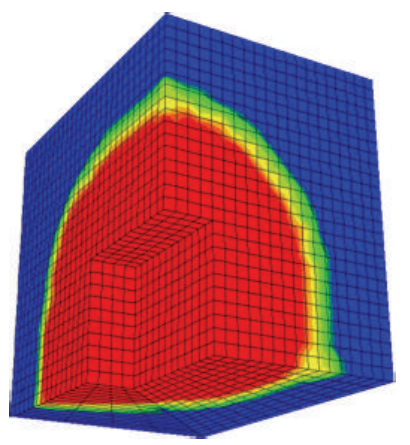

(e) Charge length is $5.0 \mathrm{~m}$
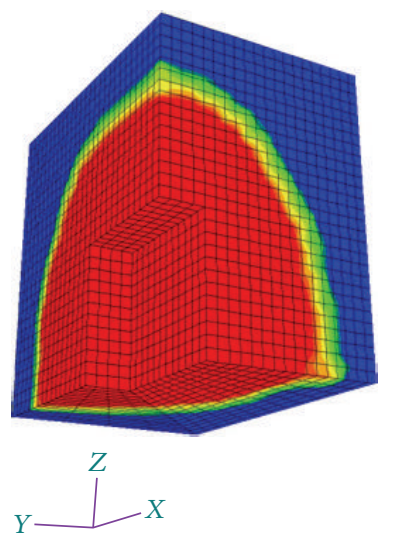

(g) Charge length is $6.0 \mathrm{~m}$

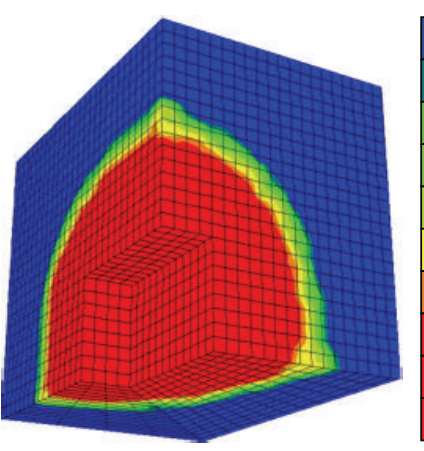

$0.0000 e+000-1.0000 e-001$ $1.0000 e-001-2.0000 e-001$ $2.0000 e-001-3.0000 e-001$ $3.0000 e-001-4.0000 e-001$ $4.0000 e-001-5.0000 e-001$ $5.0000 e-001-6.0000 e-001$ $6.0000 e-001-7.0000 e-001$ $7.0000 e-001-8.0000 e-001$ $8.0000 e-001-9.0000 e-001$ $9.0000 e-001-9.9980 e-001$

(c) Charge length is $4.0 \mathrm{~m}$

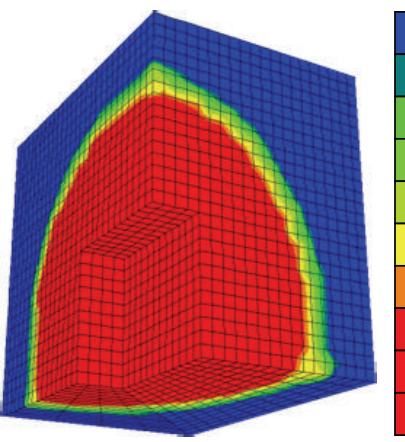

$0.0000 e+000-1.0000 e-001$

$1.0000 e-001-2.0000 e-001$

$2.0000 e-001-3.0000 e-001$

$3.0000 e-001-4.0000 e-001$

$4.0000 e-001-5.0000 e-001$

$5.0000 e-001-6.0000 e-001$

$6.0000 e-001-7.0000 e-001$

$7.0000 e-001-8.0000 e-001$

$8.0000 e-001-9.0000 e-001$

$9.0000 e-001-9.9980 e-001$

(f) Charge length is $5.5 \mathrm{~m}$

\begin{tabular}{|l}
$0.0000 e+000-1.0000 e-001$ \\
$1.0000 e-001-2.0000 e-001$ \\
$2.0000 e-001-3.0000 e-001$ \\
$3.0000 e-001-4.0000 e-001$ \\
$4.0000 e-001-5.0000 e-001$ \\
$5.0000 e-001-6.0000 e-001$ \\
$6.0000 e-001-7.0000 e-001$ \\
$7.0000 e-001-8.0000 e-001$ \\
$8.0000 e-001-9.0000 e-001$ \\
$9.0000 e-001-9.9980 e-001$
\end{tabular}

Figure 8: Damage zone after mining blasting.

The boundary conditions are the same as those in Section 2.3. because the maximum pressure varies depending on the charge and the blasting damage zone depending on the charge can be simulated by applying different pressure on the boundary of crushed zone. Mohr-Coulomb (M-C) model is considered the material model for numerical simulation [22], and the parameters are listed in Table 1. The applied dynamic loads are equal to the results calculated above.

4.2. Analysis of the Damage Characteristics. For example, when the charge length is $6 \mathrm{~m}$, the damage growth on the free surface and along the height direction is shown in Figures 6 and 7.
Figures 6 and 7 show that the rock mass is not damaged yet in $0.1 \mathrm{~ms}$ after detonation whether on the free surface or along the height direction. The damage of rock subject to blasting load needs some time to develop. In the time interval between $0.1 \mathrm{~ms}$ and $1.5 \mathrm{~ms}$, the damage zone radius is approximately $6.785 \mathrm{~m}$ and it reaches about $8.142 \mathrm{~m}$ in the time interval between $1.5 \mathrm{~ms}$ and $3.0 \mathrm{~ms}$. Combined with the above analysis, the calculation results agree well with the first two agreements (1) and (2) which are presented in Section 3.

Using the same way, the damage zone with the charge length of $3 \mathrm{~m}, 3.5 \mathrm{~m}, 4.0 \mathrm{~m}, 4.5 \mathrm{~m}, 5.0 \mathrm{~m}, 5.5 \mathrm{~m}$, and $6.0 \mathrm{~m}$ is shown in Figure 8. Damage under blasting loads grows faster within the first $1.5 \mathrm{~ms}$ after denotation than that in the latter $1.5 \mathrm{~ms}$. 


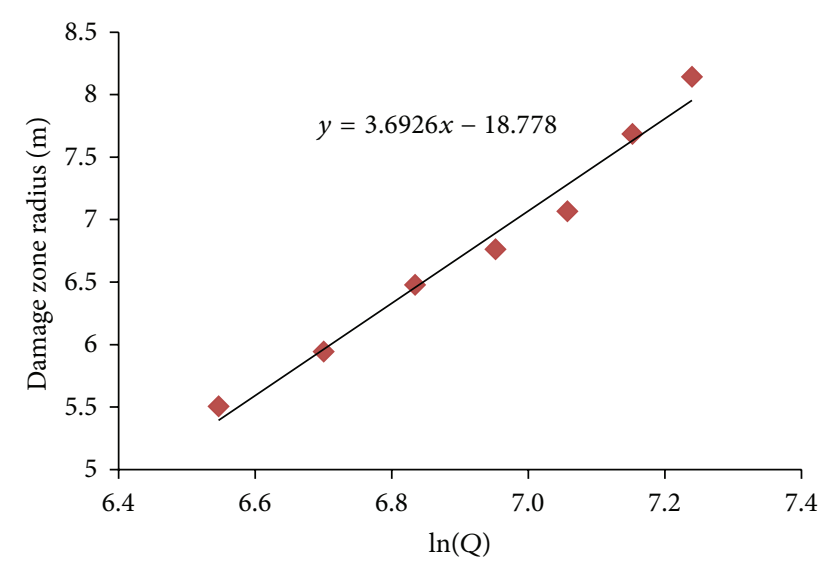

FIGURE 9: Fitting curve between damage zone radius and charge weight.

Figure 8 shows the crushed zone with the damage value of 0.2 . The damage zone radiuses are listed in Table 3 .

Based on the in-site parameters, the statistical relationship between charge amount and damage zone radius is established.

As shown in Figure 9, the function relation can be expressed by

$$
r=3.693 \ln Q-18.778 \text {, }
$$

where $r$ is damage zone radius of surrounding rock and $Q$ is one-stage charge.

The rooms and barrier pillars are $18 \mathrm{~m}$ wide. As illustrated in (11), when $r=9 \mathrm{~m}$, the maximum one-stage charge is $1848.26 \mathrm{~kg}$. So the in-site maximum one-stage charge should be less than $1848.26 \mathrm{~kg}$. The maximum one-stage charge can be precalculated by empirical formula when the blasting operation is performed at any location in the stope, so that the stope boundary can be under control, the surrounding rock mass can be stable, and the safe production can be ensured.

\section{Conclusions}

The following conclusions can be drawn.

(1) Based on statistical fracture mechanics, damage due to blasting shock load can be defined in the probability form. The damage model was established. And the damage characteristics were obtained by numerical simulation.

(2) Under blasting shock load, the rock mass is not damaged yet at the initial stage after detonation whether on the free surface or along the height direction. The damage of rock subject to blasting load needs some time to develop. Damage under blasting loads grows faster within the first $1.5 \mathrm{~ms}$ after denotation than that in the latter $1.5 \mathrm{~ms}$.

(3) According to the results in different blasting conditions, the statistical relationship between charge amount and damage zone radius is established. Furthermore, the maximum one-stage charge was proposed to be less than $1848.26 \mathrm{~kg}$ on the purpose of controlling the stope damage boundary.

\section{Conflict of Interests}

The authors declare that there is no conflict of interests regarding the publication of this paper.

\section{Acknowledgments}

The study was sponsored by the National Natural Science Foundation of China (Grant nos. 41372312 and 51379194), the Fundamental Research Funds for the Central Universities, China, University of Geosciences (Wuhan) (Grant no. CUGL140817), and the China Postdoctoral Science Foundation (Grant no. 2014M552113). The authors are also grateful to the China Scholarship Council (CSC) for the support.

\section{References}

[1] A. Palmström and R. Singh, "The deformation modulus of rock masses-comparisons between in situ tests and indirect estimates," Tunnelling and Underground Space Technology, vol. 16, no. 2, pp. 115-131, 2001.

[2] P. K. Singh, "Blast vibration damage to underground coal mines from adjacent open-pit blasting," International Journal of Rock Mechanics and Mining Sciences, vol. 39, no. 8, pp. 959-973, 2002.

[3] Y.-Q. Zhang, H. Hao, and Y. Lu, "Anisotropic dynamic damage and fragmentation of rock materials under explosive loading," International Journal of Engineering Science, vol. 41, no. 9, pp. 917-929, 2003.

[4] M. Cai, P. K. Kaiser, Y. Tasaka, T. Maejima, H. Morioka, and M. Minami, "Generalized crack initiation and crack damage stress thresholds of brittle rock masses near underground excavations," International Journal of Rock Mechanics and Mining Sciences, vol. 41, no. 5, pp. 833-847, 2004.

[5] C. Wu and H. Hao, "Numerical prediction of rock mass damage due to accidental explosions in an underground ammunition storage chamber," Shock Waves, vol. 15, no. 1, pp. 43-54, 2006.

[6] G. W. Ma and X. M. An, "Numerical simulation of blastinginduced rock fractures," International Journal of Rock Mechanics and Mining Sciences, vol. 45, no. 6, pp. 966-975, 2008.

[7] C. Wu, Y. Lu, and H. Hao, "Numerical prediction of blastinduced stress wave from large-scale underground explosion," International Journal for Numerical and Analytical Methods in Geomechanics, vol. 28, no. 1, pp. 93-109, 2004.

[8] Z. Zhu, H. Xie, and B. Mohanty, "Numerical investigation of blasting-induced damage in cylindrical rocks," International Journal of Rock Mechanics and Mining Sciences, vol. 45, no. 2, pp. 111-121, 2008.

[9] H. Hao, C. Wu, and C. C. Seah, "Numerical analysis of blastinduced stress waves in a rock mass with anisotropic continuum damage models Part 2: stochastic approach," Rock Mechanics and Rock Engineering, vol. 35, no. 2, pp. 95-108, 2002.

[10] H. Hao, C. Wu, and Y. Zhou, "Numerical analysis of blastinduced stress waves in a rock mass with anisotropic continuum damage models Part 1: equivalent material property approach," Rock Mechanics and Rock Engineering, vol. 35, no. 2, pp. 79-94, 2002. 
[11] X. Y. Wei, Z. Y. Zhao, and J. Gu, "Numerical simulations of rock mass damage induced by underground explosion," International Journal of Rock Mechanics and Mining Sciences, vol. 46, no. 7, pp. 1206-1213, 2009.

[12] Z.-L. Wang, Y.-C. Li, and R. F. Shen, "Numerical simulation of tensile damage and blast crater in brittle rock due to underground explosion," International Journal of Rock Mechanics and Mining Sciences, vol. 44, no. 5, pp. 730-738, 2007.

[13] N. Jiang and C. Zhou, "Blasting vibration safety criterion for a tunnel liner structure," Tunnelling and Underground Space Technology, vol. 32, pp. 52-57, 2012.

[14] J. O. Hallquist, LS-DYNA Keyword User's Manual, Livermore Software Technology Corporation, Livermore, Calif, USA, 2007.

[15] M. Chen, W. B. Lu, and C. P. Yi, "Blasting vibration criterion for a rock-anchored beam in an underground powerhouse," Tunnelling and Underground Space Technology, vol. 22, no. 1, pp. 6979, 2007.

[16] P. A. Persson, R. Holmberg, and J. Lee, Rock Blasting and Explosives Engineering, CRC Press, New York, NY, USA, 1993.

[17] L. Liu and P. D. Katsabanis, "Development of a continuum damage model for blasting analysis," International Journal of Rock Mechanics and Mining Sciences, vol. 34, no. 2, pp. 217-231, 1997.

[18] R. Yang, W. F. Bawden, and P. D. Katsabanis, "A new constitutive model for blast damage," International Journal of Rock Mechanics and Mining Sciences \& Geomechanics, vol. 33, no. 3, pp. 245254,1996

[19] L. Haibo, X. Xiang, L. Jianchun, Z. Jian, L. Bo, and L. Yaqun, "Rock damage control in bedrock blasting excavation for a nuclear power plant," International Journal of Rock Mechanics and Mining Sciences, vol. 48, no. 2, pp. 210-218, 2011.

[20] J. S. Kuszmaul, A New Constitutive Model for Fragmentation of Rock under Dynamic Loading, Sandia National Laboratories, Albuquerque, NM, USA, 1987.

[21] C. Zhou, N. Jiang, and G. Luo, "Study on blasting vibration cumulative damage effect of medium-length hole mining," Disaster Advances, vol. 5, no. 4, pp. 468-473, 2012.

[22] Itasca Consulting Group, Fast Lagrangian Analysis of Continua in 3 Dimensions, Version 4.0, Itasca Consulting Group, Minneapolis, Minn, USA, 2009. 

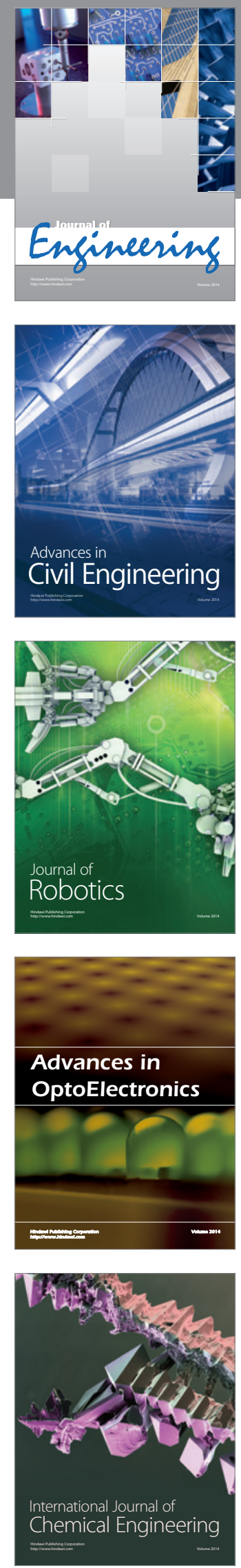

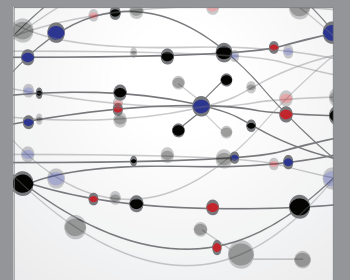

The Scientific World Journal
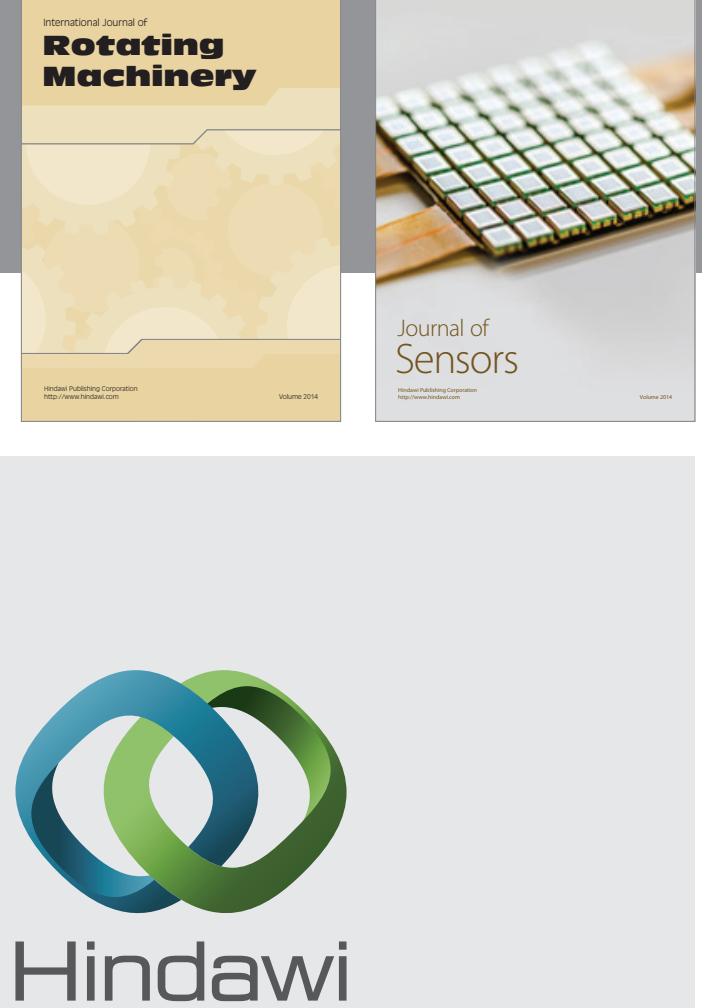

Submit your manuscripts at http://www.hindawi.com
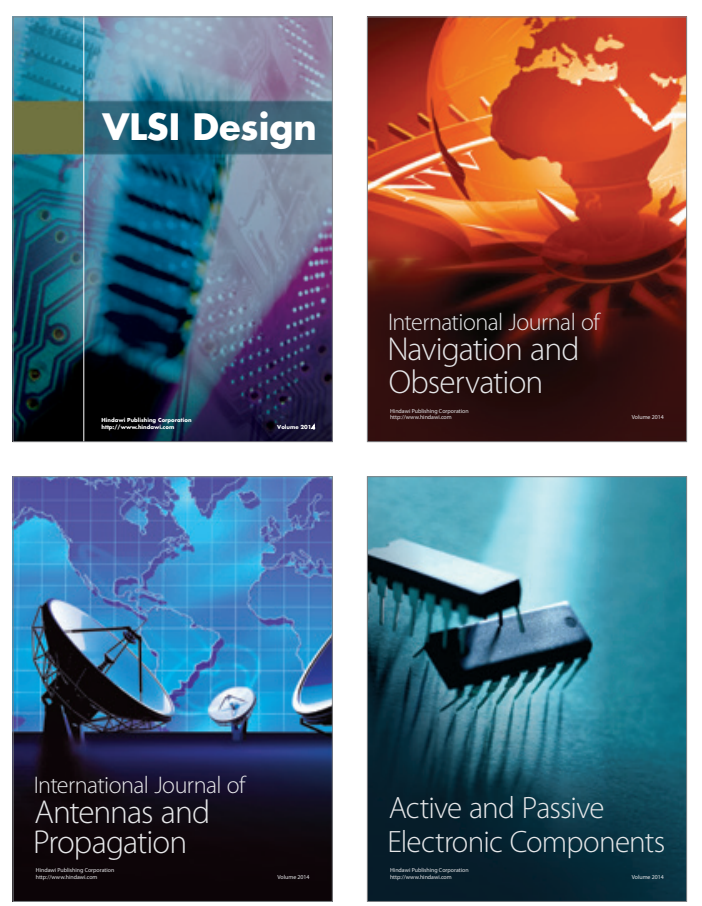
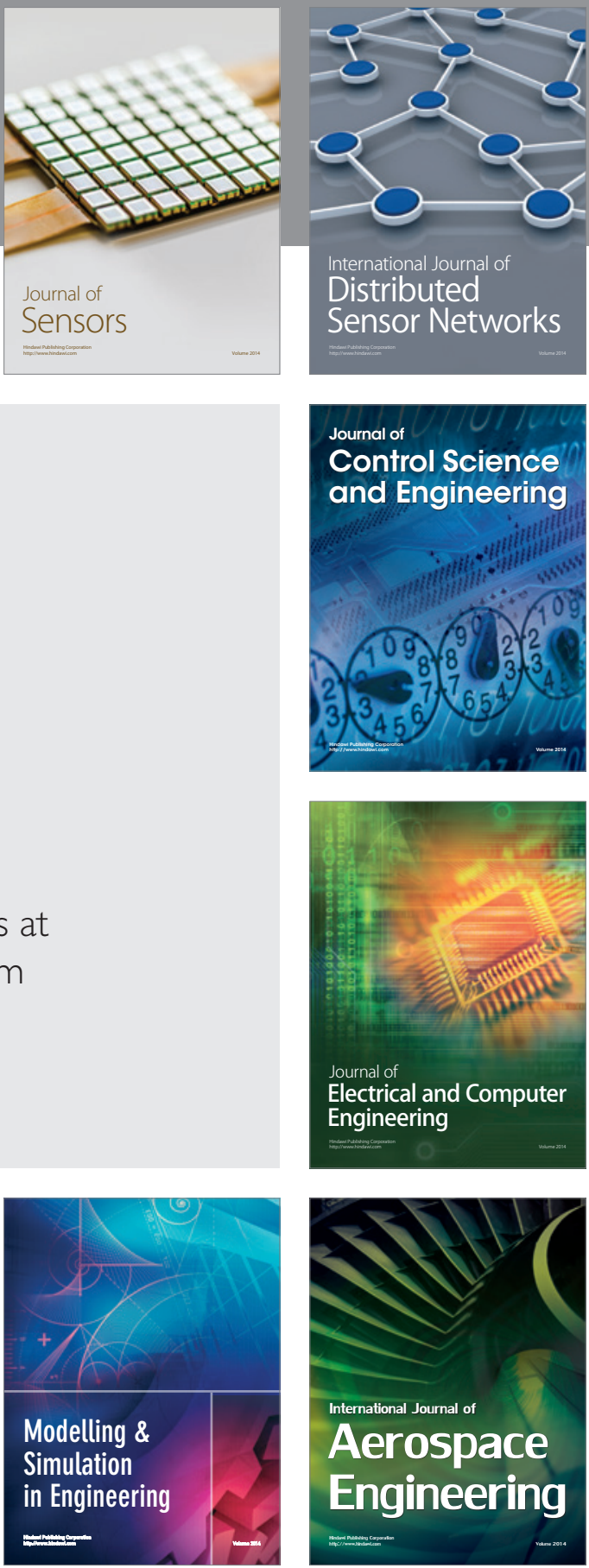

Journal of

Control Science

and Engineering
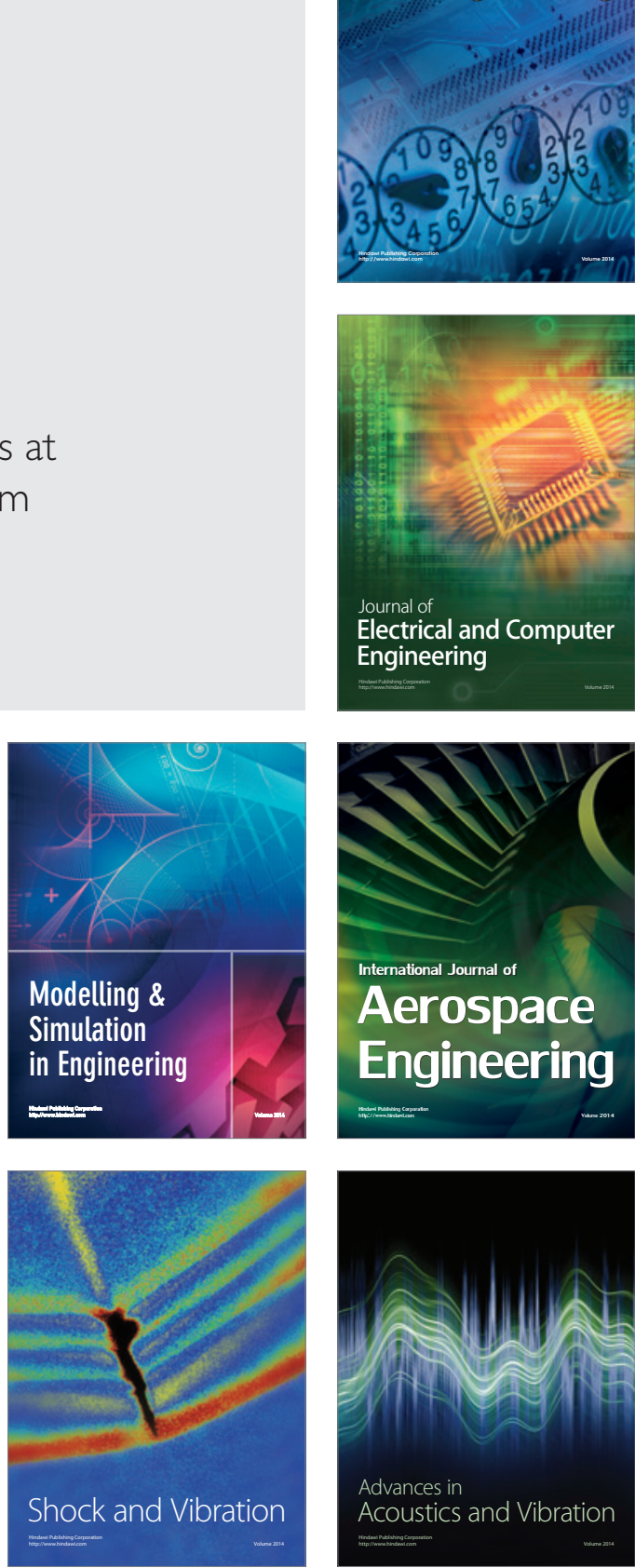